\title{
No Signs of Neuroinflammation in Women With Chronic Fatigue Syndrome or Q Fever Fatigue Syndrome Using the TSPO Ligand $\left[{ }^{11} \mathrm{C}\right]$-PK11195
}

Ruud Raijmakers, MSc, Megan Roerink, MD, Stephan Keijmel, MD, Leo Joosten, PhD, MD, Mihai Netea, PhD, MD, Jos van der Meer, PhD, MD, Hans Knoop, PhD, MD, Hans Klein, MD, Chantal Bleeker-Rovers, PhD, MD, and Janine Doorduin, MD

Neurol Neuroimmunol Neuroinflamm 2022;9:e1113. doi:10.1212/NXI.0000000000001113
Correspondence

Dr. Raijmakers

ruud.raijmakers@radboudumc.nl

\section{Abstract}

\section{Background and Objectives}

The pathophysiology of chronic fatigue syndrome (CFS) and Q fever fatigue syndrome (QFS) remains elusive. Recent data suggest a role for neuroinflammation as defined by increased expression of translocator protein (TSPO). In the present study, we investigated whether there are signs of neuroinflammation in female patients with CFS and QFS compared with healthy women, using PET with the TSPO ligand ${ }^{11} \mathrm{C}-(R)-(2$-chlorophenyl)- $N$-methyl- $N$-(1-methylpropyl)3-isoquinoline-carbox-amide ([ $\left.\left.{ }^{11} \mathrm{C}\right]-\mathrm{PK} 11195\right)$.

\section{Methods}

The study population consisted of patients with CFS $(n=9)$, patients with QFS $(n=10)$, and healthy subjects $(\mathrm{HSs})(\mathrm{n}=9)$. All subjects were women, matched for age $( \pm 5$ years $)$ and neighborhood, aged between 18 and 59 years, who did not use any medication other than paracetamol or oral contraceptives, and were not vaccinated in the last 6 months. None of the subjects reported substance abuse in the past 3 months or reported signs of underlying psychiatric disease on the Mini-International Neuropsychiatric Interview. All subjects underwent a $\left[{ }^{11} \mathrm{C}\right]-\mathrm{PK} 11195 \mathrm{PET}$ scan, and the $\left[{ }^{11} \mathrm{C}\right]-\mathrm{PK} 11195$ binding potential $\left(\mathrm{BP}_{\mathrm{ND}}\right)$ was calculated.

\section{Results}

No statistically significant differences in $\mathrm{BP}_{\mathrm{ND}}$ were found for patients with $\mathrm{CFS}$ or patients with QFS compared with HSs. $\mathrm{BP}_{\mathrm{ND}}$ of $\left[{ }^{11} \mathrm{C}\right]$-PK11195 correlated with symptom severity scores in patients with QFS, but a negative correlation was found in patients with CFS.

\section{Discussion}

In contrast to what was previously reported for CFS, we found no significant difference in $\mathrm{BP}_{\mathrm{ND}}$ of $\left[{ }^{11} \mathrm{C}\right]$-PK11195 when comparing patients with CFS or QFS with healthy neighborhood controls. In this small series, we were unable to find signs of neuroinflammation in patients with CFS and QFS.

\section{Trial Registration Information}

EudraCT number 2014-004448-37. 


\section{Glossary}

$\left[{ }^{11} \mathrm{C}\right]-\mathrm{PK} 11195={ }^{11} \mathrm{C}$-(R)-(2-chlorophenyl)-N-methyl- $N$-(1-methylpropyl)-3-isoquinoline-carbox-amide; BDI-PC = Beck Depression Inventory for Primary Care; BP = binding potential; CDC = Centers for Disease Control; CFS = chronic fatigue syndrome; CIS = Checklist Individual Strength; HS = healthy subject; Ig = immunoglobulin; QFS = Q fever fatigue syndrome; SIP-8 $=$ Sickness Impact Profile $8 ;$ TSPO $=$ translocator protein .

Chronic fatigue syndrome (CFS) is characterized by a debilitating fatigue without a known somatic cause that lasts for at least 6 months and is often accompanied by headache, sore throat, musculoskeletal pain, and neuropsychological symptoms, mainly impairments in memory and concentration. ${ }^{1}$ There is a strong female preponderance in CFS $(\sim 75 \%)$. Previous research on CFS investigating metabolism, hormones, microbes, the immune system, and neuropsychology failed to discover a unifying pathogenesis. ${ }^{2-6}$ Many patients with CFS had a previous infectious disease and are considered as postinfectious fatigue syndromes. ${ }^{7,8} \mathrm{Q}$ fever fatigue syndrome (QFS) is such a postinfectious fatigue syndrome that is characterized by a state of prolonged fatigue following approximately $20 \%$ of acute $Q$ fever infections. ${ }^{9,10}$ The fatigue lasts for at least 6 months and usually coincides with musculoskeletal complaints, neurocognitive problems, sleeping problems, headache, respiratory tract symptoms, and mood disorders. ${ }^{9}$ In many ways, complaints of QFS are similar as to those reported by patients with CFS, and like in CFS, the pathophysiology of QFS is still unclear. ${ }^{11}$

Given the complaints that patients with CFS and patients with QFS have, it is conceivable that both an inflammatory and neurologic component contribute to their pathophysiology. ${ }^{5,12,13} \mathrm{~A}$ hypothesis that connects these pathophysiologic components is that of chronic low-grade neuroinflammation. ${ }^{5}$ Within the context of this hypothesis, a peripheral inflammatory response, for example, initiated by $\mathrm{Q}$ fever, ultimately extends to resident tissue macrophages, that is, microglia, of the brain. ${ }^{14}$ Trained immunity of microglia occurs following an inflammatory or noxious stimulus. This initial stimulus elicits long-term changes that enable these cells to produce an enhanced inflammatory response on a second, nonspecific, stimulus. In this way, chronic low-grade neuroinflammation may persist following a transient single infectious insult. ${ }^{15}$ Microglia may be indirectly primed through active and passive transport of cytokines across the blood-brain barrier and stimulation of peripheral chemoreceptors of the vagal nerve. $^{16}$

Through investigation of inflammatory markers in CSF, MR spectroscopy, and PET, several studies point toward neuroinflammation occurring in CFS. ${ }^{5,17-19}$ As microglial activation is its trademark characteristic, visualizing neuroinflammation is best done by PET neuroimaging using a radioligand that binds to the, increased expression of, $18-\mathrm{kD}$ translocator protein (TSPO) in activated microglia and astrocytes. ${ }^{16}$ In recent years, Nakatomi et al. ${ }^{5}$ showed that compared with healthy subjects (HSs), patients with CFS exhibit an increased PET signal, especially at the thalamus, showing positive correlation with pain scores, when using the ${ }^{11} \mathrm{C}$ (R)-(2-chlorophenyl)- $N$-methyl- $N$-(1-methylpropyl)-3isoquinoline-carbox-amide ([ $\left.\left.{ }^{11} \mathrm{C}\right]-\mathrm{PK} 11195\right)$ ligand for TSPO. These and other findings ${ }^{20,21}$ suggest that patients with CFS exhibit neuroinflammation and that this phenomenon warrants further investigation in the pathophysiology of CFSs. Given the overlap in symptoms with patients with CFS and apparent inflammatory etiology, we expect patients with QFS to exhibit similar or more signs of neuroinflammation than patients with CFS.

This study aimed to confirm and further investigate a neuroinflammatory substrate in patients with CFS and QFS by using the TSPO ligand $\left[{ }^{11} \mathrm{C}\right]-\mathrm{PK} 11195$ for PET neuroimaging. Through analysis of questionnaires, we intended to correlate findings of neuroinflammation with psychiatric and physical well-being.

\section{Methods}

\section{Study Population}

The study population consisted of patients with CFS ( $\mathrm{n}=$ $9)$, patients with QFS $(\mathrm{n}=10)$, and HSs $(\mathrm{n}=9)$. For reasons of homogeneity, all subjects were women and matched for age ( \pm 5 years) and neighborhood. All subjects were aged between 18 and 59 years, did not use any medication other than paracetamol or oral contraceptives, and were not vaccinated in the last 6 months. None of the subjects reported substance abuse in the past 3 months or showed signs of underlying psychiatric disease, that is, depression, bipolar disorders, anxiety, schizophrenia, psychosis, or eating disorders on Mini-International Neuropsychiatric Interview.

All patients with CFS were diagnosed with CFS at the Department of Internal Medicine and Expert Center for Chronic Fatigue of the Radboud University Medical Center, Nijmegen, the Netherlands, after a uniform workup according to the Fukuda 1994 criteria for CFS. ${ }^{1,22}$ They all had a score $\geq 40$ on the subscale fatigue severity of the Checklist Individual Strength (CIS) questionnaire ${ }^{23}$ and a score $\geq 700$ on the Sickness Impact Profile 8 (SIP-8) questionnaire. ${ }^{24}$ None of them experienced an acute $Q$ fever infection or were vaccinated against $\mathrm{Q}$ fever in the past. Coxiella PCR and immunoglobulin $\mathrm{G}$ ( $\mathrm{IgG}$ ) were not tested, and no data were collected on whether an infection preceded CFS complaints. 
All patients with QFS were diagnosed at the Radboud Expert Center for $\mathrm{Q}$ fever, Nijmegen, the Netherlands, after a uniform workup according to the Dutch guideline on QFS diagnosis. ${ }^{25}$ All patients with QFS met the following diagnostic criteria: (i) fatigue lasted $\geq 6$ months; (2) sudden onset of severe fatigue (defined as a score $\geq 40$ on the subscale fatigue severity of the CIS) or significant increase in fatigue, both related to a symptomatic acute $Q$ fever infection; (3) chronic $Q$ fever and other somatic or psychiatric causes of fatigue were excluded; and (4) fatigue resulted in significant functional impairment (defined as a total score $\geq 700$ on the SIP- 8 questionnaire). All patients with QFS tested negative on Coxiella PCR and had IgG phase I or phase II titers $\geq 1: 16$, but IgG phase $\mathrm{I} \leq 1: 512$, and none of them showed serologic signs of an acute or recent Q-fever infection, reflected by IgM antibodies in the absence of IgG antibodies.

HSs were recruited based on age, sex, and neighborhood that matched with both patients with QFS and CFS and had a score $\leq 35$ on the subscale fatigue severity of the CIS questionnaire and a score $\leq 450$ on the SIP- 8 questionnaire. Similar to patients, HSs did not use any medication other than paracetamol or contraceptives and were screened for psychiatric disease. None of the HSs had experienced acute Q fever infection or were vaccinated for Q fever. Coxiella PCR and IgG were not tested.

The sample size needed was estimated using the effect size (Cohen d) as calculated from a previous $\left[{ }^{11} \mathrm{C}\right]-\mathrm{PK} 11195$ study by Nakatomi et al. in 9 patients with CFS vs $10 \mathrm{HSs}^{5}$ and the $\left[{ }^{11} \mathrm{C}\right]$-PK11195 binding potential $\left(\mathrm{BP}_{\mathrm{ND}}\right)$ in HSs from a previous study performed by our group. ${ }^{26}$ Effect sizes of the $\mathrm{BP}_{\mathrm{ND}}$ for the different brain regions included by Nakatomi et al. ${ }^{5}$ ranged from 1.4 (hippocampus) to 2.4 (midbrain). Using these effect sizes, the $\mathrm{BP}_{\mathrm{ND}}$ in patients with $\mathrm{CFS}$ was estimated from the $\mathrm{BP}_{\mathrm{ND}}$ in HSs. For example, the $\mathrm{BP}_{\mathrm{ND}}$ of the hippocampus in HSs was $1.37 \pm 0.30$, leading to an estimated $\mathrm{BP}_{\mathrm{ND}}$ of 1.79 (effect size of 1.4) or 2.84 (effect size of 2.4) in patients with CFS. Based on these estimations, and using an alpha of 0.05 and a power of 0.80 , it was estimated that a group size of 9 (effect size of 1.4) to 3 (effect size of 2.4) was sufficient for finding significant differences in the $\mathrm{BP}_{\mathrm{ND}}$. Based on these calculations and the study by Nakatomi et al., we have chosen a group size with a minimum of $n=9$.

\section{Questionnaires}

All subjects were asked to fill out questionnaires, used in our expert centers, ${ }^{23}$ on CFS aspects previously associated with neuroinflammation, that is, depression, concomitant CFS complaints, and fatigue: ${ }^{5,27}$

CIS, subscale on fatigue severity, assesses the severity of fatigue, which is part of the inclusion criteria. ${ }^{23}$

SIP-8 assesses the influence of disease and/or health complaints on functioning in daily life, which is part of the inclusion criteria. ${ }^{24}$
BDI-II-NL-PC Beck Depression Inventory for Primary Care (BDI-PC, shortened) assesses depressive symptoms. ${ }^{28}$

Centers for Disease Control (CDC) CFS Symptom Inventory Questionnaire, subscale on active complaints, assesses concomitant CFS symptoms. ${ }^{29}$

\section{PET Imaging}

Following testing for collateral blood flow and the injection of $1 \%$ lidocaine, a cannula was inserted in the radial artery to allow for arterial blood sampling. In the other arm, a cannula was placed in the antebrachial vein for the injection of $\left[{ }^{11} \mathrm{C}\right]$ PK11195. The PET scans were performed using the Biograph mCT (Siemens Healthineers, Germany). Head movement was minimized by using a head-restraining adhesive band. After positioning in the camera, a low-dose CT scan was made for attenuation and scatter correction. Hereafter, $\left[{ }^{11} \mathrm{C}\right]$ PK11195, produced under Good Manufacturing Practice conditions as described earlier, ${ }^{26}$ was injected IV at a speed of $0.5 \mathrm{~mL} / \mathrm{s}$ (total volume $8.3 \mathrm{~mL}$ ). The injected dose of $\left[{ }^{11} \mathrm{C}\right]$ PK11195 was $367 \pm 50 \mathrm{MBq}$ (HSs, $370 \pm 53 \mathrm{MBq}$; CFS, 375 $\pm 37 \mathrm{MBq}$, QFS, $356 \pm 55 \mathrm{MBq}$ ) with a molar activity of $>12,000 \mathrm{GBq} / \mathrm{mmoL}$. Simultaneously with the start of the injection, a 60-minute emission scan was started during which arterial blood radioactivity was continuously measured with an automated blood sampling system (COMECER Netherlands, the Netherlands). Five manual blood samples were collected at 10,20,30, 45, and 60 minutes after $\left[{ }^{11} \mathrm{C}\right]$ PK11195 injection to determine the amount of radioactivity in blood and plasma for calibration of the automated sampling system. The manual blood samples taken at 20,45 , and 60 minutes were additionally used for analysis of the percentage of intact $\left[{ }^{11} \mathrm{C}\right]-\mathrm{PK} 11195$ in plasma, according to the procedure described previously. ${ }^{26}$ On the same day as the PET scan, a T1-weighted MRI scan, using a MAGNETOM Prisma (Siemens Healthineers, Germany), was made for anatomic reference.

\section{PET Data Analysis}

The list-mode data from the PET scans were reconstructed using the 3D OSEM algorithm ( 3 iterations and 24 subsets) into 24 successive frames $\left(7^{*} 10,2^{*} 30,2^{*} 120,2^{*} 180,5^{*} 300\right.$, and $2^{*} 600$ seconds). Image processing and pharmacokinetic analysis were performed with PMOD software v4.1 (PMOD Technologies Ltd., Switzerland). The summed PET image (frame 1-24) was used for rigid registration of the individual PET image to the individual MRI. The 6-tissue probability map normalization of the individual MRI into the Montreal Neurological Institute standard space was then performed and applied to the corresponding PET image. Predefined volumes of interest, based on the Hammers atlas, ${ }^{30}$ were transformed back into individual PET space, and time activity curves were generated.

The 2-tissue compartment model was used to obtain the nondisplaceable $\mathrm{BP}_{\mathrm{ND}}$ of $\left[{ }^{11} \mathrm{C}\right]-\mathrm{PK} 11195$, using the metabolitecorrected plasma curve as the input function. The delay and the 
blood volume were individually fitted. It was assumed that the distribution volume of the nondisplaceable compartment $\left(\mathrm{K}_{1} / \mathrm{k}_{2}\right)$ and the dissociation rate $\left(\mathrm{k}_{4}\right)$ from the specific binding site were equal for all regions. A coupled fitting was performed for cortical regions that calculated a common $\mathrm{K}_{1} / \mathrm{k}_{2}$ and $\mathrm{k}_{4}$, which were then used to calculate an individual $\mathrm{K}_{1}$ and $\mathrm{k}_{3}$ for all regions. The $\mathrm{BP}_{\mathrm{ND}}$ was defined as $\mathrm{k}_{3} / \mathrm{k}_{4}$.

\section{Statistical Analysis}

Patient data were analyzed using GraphPad Prism (GraphPad Software Inc., version 5.03). An ANOVA was used to determine differences between groups. A Pearson correlation was used to determine correlations between $\mathrm{BP}_{\mathrm{ND}}$ of $\left[{ }^{11} \mathrm{C}\right]$ PK11195 in various brain regions and symptom severity scores in patients with CFS and QFS. Statistical significance was attained if $p<0.05$.

\section{Standard Protocol Approvals, Registrations, and Patient Consents}

All participants provided written informed consent, and the study was approved by the Medical Ethical Review Committee of the University Medical Center Groningen (UMCG NL51194.042.15).

\section{Data Availability}

The data sets used and/or analyzed during the current study are available from the corresponding author on reasonable request.

\section{Results}

\section{Patients and Controls}

At the time of PET imaging, patients with CFS had a significantly longer median duration of illness than patients with QFS ( 240 vs 84 months, $p=0.01$ ). The median age of patients with CFS, patients with QFS, and HSs did not differ significantly (Table 1). Other than the fact that patients with CFS were significantly more functionally impaired than patients with QFS $(p=0.02)$, no significant differences in other scores were found between patients with CFS and QFS (Table 1).

\section{$\mathrm{BP}_{\mathrm{ND}}$ of $\left[{ }^{11} \mathrm{C}\right]-\mathrm{PK} 11195$ in Various Brain Regions} The $\mathrm{BP}_{\mathrm{ND}}$ of $\left[{ }^{11} \mathrm{C}\right]-\mathrm{PK} 11195$ in various brain regions for patients with CFS and QFS compared with HSs was not significantly different (Figure 1 and Table 2). No differences were found in $\mathrm{BP}_{\mathrm{ND}}$ values comparing means of patients with CFS and QFS with HSs for the cingulate (rostral anterior: mean difference -0.33 [95\% CI, -0.82 to 0.17 ] and -0.30 [95\% CI, -0.77 to 0.17 ] with $p=0.30$ and 0.33 , respectively, caudal anterior: mean difference -0.33 [95\% CI, -0.83 to 0.16 ] and -0.20 [95\% CI, -0.67 to 0.27$]$ with $p=0.29$ and 0.83 , respectively, posterior: mean difference -0.32 [95\% CI, -0.85 to 0.22 ] and -0.18 [95\% CI, -0.69 to 0.33 ] with $p=$ 0.43 and 1.00, respectively), hippocampus (mean difference -0.37 [ $95 \% \mathrm{CI},-0.90$ to 0.16 ] and -0.23 [95\% CI, -0.73 to 0.27 with $p=0.25$ and 0.73 , respectively), thalamus (mean difference -0.32 [95\% CI, -0.94 to 0.31 ] and -0.20 [95\% CI,
-0.80 to 0.39$]$ with $p=0.61$ and 1.00 , respectively), midbrain (mean difference -0.40 [95\% CI, -1.06 to 0.25$]$ and -0.33 [95\% CI, -0.95 to 0.29 ] with $p=0.38$ and 0.54 , respectively), or pons (mean difference -0.44 [95\% CI, -1.23 to 0.36$]$ and -0.30 [95\% CI, -1.05 to 0.45$]$ with $p=0.51$ and 0.95 , respectively). In fact, as seen by the mean difference, $\mathrm{BP}_{\mathrm{ND}}$ values tended to be lower rather than higher for both patients with CFS and QFS compared with HSs.

\section{Correlation Between Symptom Severity Scores and $\mathrm{BP}_{\mathrm{ND}}$ of $\left[{ }^{11} \mathrm{C}\right]-\mathrm{PK} 11195$}

Significant correlations between symptom severity scores and $\mathrm{BP}_{\mathrm{ND}}$ of $\left[{ }^{11} \mathrm{C}\right]-\mathrm{PK} 11195$ in various brain regions of both patients with CFS and patients with QFS are shown in eTable 1 (links.lww.com/NXI/A662). For patients with CFS, the CDC questionnaire, subscale on complaints, and the CIS questionnaire, subscale fatigue severity, correlated with $\mathrm{BP}_{\mathrm{ND}}$ in the caudate nucleus $(-0.73, p<0.05$ and $-0.78, p<0.05$, respectively) (eTable 1) (Figure 2 and 3 ). For patients with QFS, the CDC questionnaire, subscale on complaints, correlated with $\mathrm{BP}_{\mathrm{ND}}$ in the brainstem $(0.66, p<0.05)$, caudal anterior cingulate $(0.64, p<0.05)$, insula $(0.65, p<0.05)$, amygdala $(0.71, p<0.05)$, and pons $(0.69, p<0.05)$, and the CIS questionnaire, subscale on fatigue severity, correlated with $\mathrm{BP}_{\mathrm{ND}}$ in the orbitofrontal cortex $(0.70, p<0.05)$, middle frontal gyrus $(0.83, p<0.01)$, inferior frontal gyrus $(0.78, p<$ $0.01)$, superior frontal gyrus $(0.64, p<0.05)$, primary motor cortex $(0.74, p<0.05)$, temporal lobe $(0.78, p<0.01)$, primary somatosensory cortex $(0.83, p<0.01)$, and parietal lobe $(0.77$, $p<0.01$ ) (eTable 1) (Figure 2 and 3). In HSs, no significant correlations were found between symptom severity scores and $\mathrm{BP}_{\mathrm{ND}}$ of $\left[{ }^{11} \mathrm{C}\right]-\mathrm{PK} 11195$ (eTable 1$)$.

\section{Discussion}

In this study, we aimed to investigate neuroinflammation in patients with CFS and QFS by using the TSPO ligand $\left[{ }^{11} \mathrm{C}\right]$ PK11195 for PET neuroimaging. No signs of neuroinflammation were seen in either patients with CFS or QFS. Our findings contradict previous findings in patients with CFS by Nakatomi et al. ${ }^{5}$ who found significantly increased $\mathrm{BP}_{\mathrm{ND}}$ values in the cingulate, hippocampus, thalamus, midbrain, and pons. Although no signs of neuroinflammation were found, similar correlations between $\mathrm{BP}_{\mathrm{ND}}$ of $\left[{ }^{11} \mathrm{C}\right]$-PK11195 and scores on questionnaires were found in the amygdala of patients with QFS, but not patients with CFS.

Although the setup of this study was similar to that of Nakatomi et al. ${ }^{5}$, using the same TSPO ligand $\left(\left[{ }^{11} \mathrm{C}\right]\right.$ PK11195), a number of important differences can be discerned. First of all, for reasons of homogeneity, our study only included women. Around $75 \%$ of patients with CFS are female, and although the percentage of women in QFS is lower $(52 \%),{ }^{11,31}$ we felt that we should avoid a sex effect in a study with such a small sample size. Nakatomi et al. included $30 \%-40 \%$ males without presenting separate data for men 
Table 1 Characteristics of Female Patients With QFS, Patients With CFS, and HSs

\begin{tabular}{llll}
\hline Characteristics & QFS $(\mathbf{n}=\mathbf{1 0})$ & CFS $(\mathbf{n}=\mathbf{9})$ & HSs $(\mathbf{n}=\mathbf{9})$ \\
\hline $\begin{array}{l}\text { Age, } \mathbf{y} \\
\text { Median (IQR) }\end{array}$ & $43(32-48)$ & $43(30-52)$ & $41(27-47)$ \\
\hline $\begin{array}{l}\text { Duration of symptoms, mo } \\
\text { Median (IQR) }\end{array}$ & $84(74-93)$ & $240(84-390)$ \\
\hline CIS subscale fatigue severity score mean \pm SD & $50 \pm 4.7$ & $49 \pm 5.0$ \\
\hline SIP-8 total score, mean \pm SD & $1,432 \pm 362$ & $1890 \pm 395$ \\
\hline BDI-II-NL-PC score, mean \pm SD & $2.1 \pm 1.5$ & $3.8 \pm 2.7$ & $12 \pm 5.1$ \\
\hline CDC subscale on complaints score, mean \pm SD & $16 \pm 4.1$ & $17 \pm 4.5$ \\
\hline
\end{tabular}

Abbreviations: $\mathrm{CDC}=$ Centers For Disease Control; $\mathrm{CFS}=$ chronic fatigue syndrome; $\mathrm{CIS}=$ Checklist Individual Strength; HS = healthy subject; $I \mathrm{QR}=$ interquartile range; QFS = Q fever fatigue syndrome; SIP-8 = Sickness Impact Profile 8, BDI-II-NL-PC = Beck Depression Inventory for Primary Care.

a Symptom duration: time onset of symptoms until blood sampling.

and women. ${ }^{5,31}$ This is important as inflammatory responses are generally higher in males. ${ }^{32}$ Also, in experimental mouse studies of traumatic brain injury, male mice are more likely to exhibit neuroinflammation compared with female mice. ${ }^{33}$ One could argue that neuroinflammation is more likely to occur, and perhaps even persist, in males compared with females. However, if neuroinflammation is indeed present, the high percentage of female patients with CFS contradicts with this hypothesis. A second difference between our study and that of Nakatomi et al. is that we distinguished patients with CFS, with often heterogenic etiologies, ${ }^{5,31}$ from patients with postinfectious fatigue syndrome, that is, patients with QFS. Third, we used a neighborhood control group with healthy women who were matched with patients with CFS and QFS in terms of age and geographical area to accomplish optimal matching and avoid bias due to confounding. Also, patients, especially those with CFS, who were included in our study had a longer duration of illness than those included in the study by Nakatomi et al. (reported mean of 62.4 months). ${ }^{5}$ When using small numbers of included patients, as is the case in both studies, subtle differences like these might contribute to the different outcomes that are seen. This brings us to a fifth and final difference, that is, the method used for determining the binding of $\left[{ }^{11} \mathrm{C}\right]-\mathrm{PK} 11195$. We used pharmacokinetic binding with an arterial input function, whereas Nakatomi et al. used the cerebellum as a reference region in reference tissue modeling. We feel that the latter is methodologically less sound as no brain region is devoid of TSPO, meaning that the cerebellum is not an objective reference region, and the cerebellum may actually be involved in the disease process.

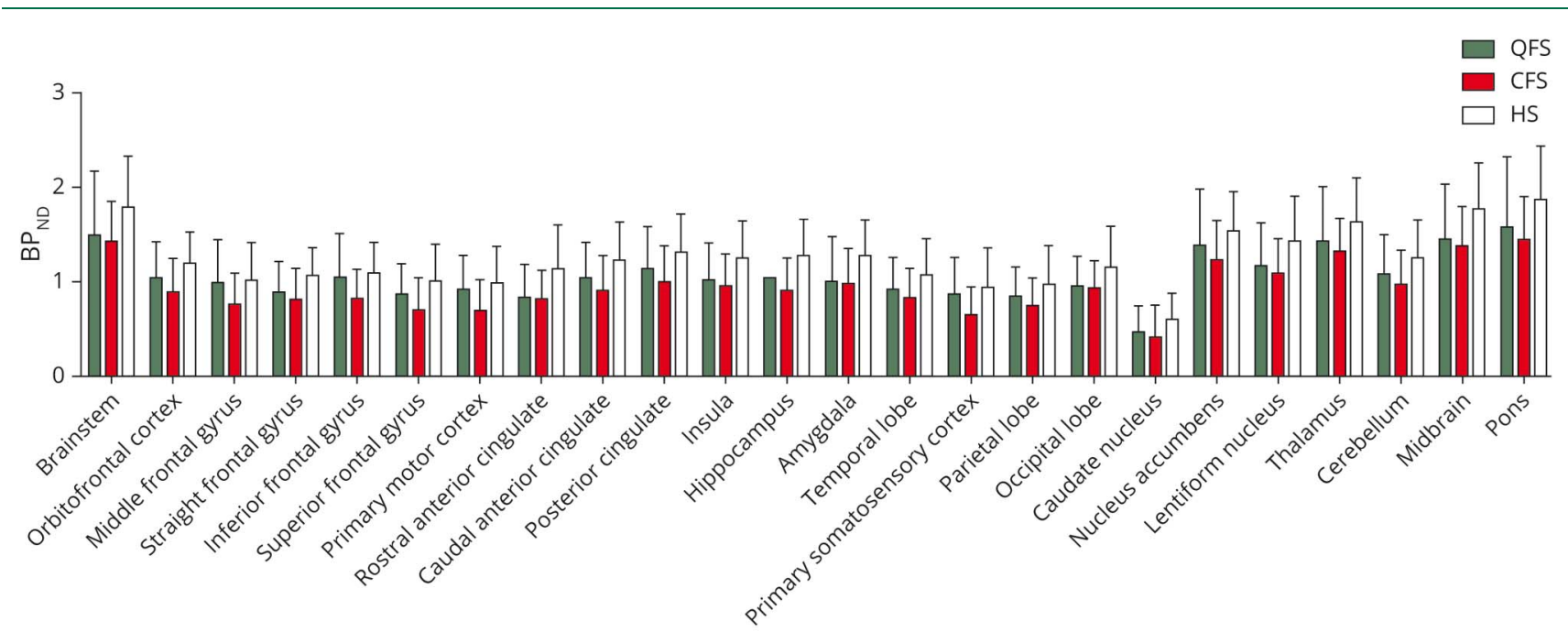

Brain region

Graph showing $\mathrm{BP}_{\mathrm{ND}}$ of $\left[{ }^{11} \mathrm{C}\right]-\mathrm{PK} 11195$ per brain region for patients with $\mathrm{QFS}$, patients with $\mathrm{CFS}$, and HSs. Data are depicted as mean \pm SD. BP ${ }_{\mathrm{ND}}=$ nondisplaceable binding potential; CFS = chronic fatigue syndrome; HS = healthy subject; QFS = Q fever fatigue syndrome. 
Table 2 BP $_{\text {ND }}$ of $\left[{ }^{11} \mathrm{C}\right]-$ PK11195 for Various Brain Regions in Patients With QFS and CFS Compared With HSs

\begin{tabular}{|c|c|c|c|c|c|}
\hline Brain region & $\begin{array}{l}\text { QFS } \\
\text { Mean }(95 \% \mathrm{CI})\end{array}$ & $\begin{array}{l}\text { CFS } \\
\text { Mean }(95 \% \mathrm{Cl})\end{array}$ & $\begin{array}{l}\text { HS } \\
\text { Mean }(95 \% \mathrm{Cl})\end{array}$ & $\begin{array}{l}\text { QFS vs HS } \\
\text { Mean difference } \\
(95 \% \mathrm{CI}), p \text { value }^{a}\end{array}$ & $\begin{array}{l}\text { CFS vs HS } \\
\text { Mean difference } \\
(95 \% \mathrm{Cl}), p \text { value }^{a}\end{array}$ \\
\hline Brainstem & $1.49(1.00-1.98)$ & $1.42(1.06-1.78)$ & $1.79(1.34-2.24)$ & $-0.30(-1.00$ to 0.40$), 0.84$ & $-0.37(-1.11$ to 0.37$), 0.63$ \\
\hline Orbitofrontal cortex & $1.04(0.77-1.31)$ & $0.89(0.60-1.18)$ & $1.20(0.93-1.48)$ & $-0.16(-0.60$ to 0.28$), 1.00$ & $-0.31(-0.77$ to 0.15$), 0.28$ \\
\hline Middle frontal gyrus & $0.99(0.66-1.32)$ & $0.76(0.48-1.04)$ & $1.02(0.69-1.35)$ & $-0.04(-0.53$ to 0.46$), 1.00$ & $-0.27(-0.79$ to 0.26$), 0.61$ \\
\hline Straight frontal gyrus & $0.89(0.66-1.12)$ & $0.81(0.54-1.09)$ & $1.07(0.82-1.32)$ & $-0.18(-0.57$ to 0.20$), 0.70$ & $-0.26(-0.67$ to 0.15$), 0.35$ \\
\hline Inferior frontal gyrus & $1.05(0.72-1.38)$ & $0.81(0.54-1.08)$ & $1.09(0.82-1.37)$ & $-0.44(-0.51$ to 0.42$), 1.00$ & $-0.29(-0.78$ to 0.21$), 0.44$ \\
\hline Superior frontal gyrus & $0.88(0.66-1.10)$ & $0.71(0.42-0.99)$ & $1.02(0.70-1.33)$ & $-0.14(-0.56$ to 0.28$), 1.00$ & $-0.31(-0.75$ to 0.14$), 0.26$ \\
\hline Primary motor cortex & $0.92(0.66-1.18)$ & $0.70(0.42-0.97)$ & $0.99(0.68-1.31)$ & $-0.08(-0.51$ to 0.36$), 1.00$ & $-0.30(-0.76$ to 0.16$), 0.33$ \\
\hline Rostral anterior cingulate & $0.84(0.59-1.09)$ & $0.81(0.55-1.07)$ & $1.14(0.75-1.53)$ & $-0.30(-0.77$ to 0.17$), 0.33$ & $-0.33(-0.82$ to 0.17$), 0.30$ \\
\hline Caudal anterior cingulate & $1.04(0.76-1.31)$ & $0.91(0.60-1.22)$ & $1.24(0.91-1.57)$ & $-0.20(-0.67$ to 0.27$), 0.83$ & $-0.33(-0.83$ to 0.16$), 0.29$ \\
\hline Posterior cingulate & $1.14(0.81-1.46)$ & $1.00(0.68-1.32)$ & $1.32(1.00-1.65)$ & $-0.18(-0.69$ to 0.33$), 1.00$ & $-0.32(-0.85$ to 0.22$), 0.43$ \\
\hline Insula & $1.02(0.74-1.30)$ & $0.96(0.69-1.23)$ & $1.26(0.93-1.58)$ & $-0.23(-0.69$ to 0.22$), 0.60$ & $-0.29(-0.77$ to 0.19$), 0.39$ \\
\hline Hippocampus & $1.04(0.71-1.37)$ & $0.90(0.62-1.19)$ & $1.27(0.95-1.60)$ & $-0.23(-0.73$ to 0.27$), 0.73$ & $-0.37(-0.90$ to 0.16$), 0.25$ \\
\hline Amygdala & $1.01(0.68-1.35)$ & $0.98(0.67-1.29)$ & $1.28(0.96-1.60)$ & $-0.26(-0.77$ to 0.25$), 0.60$ & $-0.30(-0.83$ to 0.24$), 0.50$ \\
\hline Temporal lobe & $0.92(0.67-1.16)$ & $0.83(0.58-1.09)$ & $1.08(0.76-1.39)$ & $-0.16(-0.58$ to 0.26$), 1.00$ & $-0.24(-0.69$ to 0.20$), 0.52$ \\
\hline Primary somatosensory cortex & $0.87(0.59-1.15)$ & $0.65(0.41-0.90)$ & $0.95(0.60-1.29)$ & $-0.08(-0.53$ to 0.38$), 1.00$ & $-0.30(-0.77$ to 0.18$), 0.37$ \\
\hline Parietal lobe & $0.84(0.62-1.10)$ & $0.75(0.51-0.99)$ & $0.97(0.63-1.32)$ & $-0.13(-0.54$ to 0.28$), 1.00$ & $-0.23(-0.66$ to 0.21$), 0.58$ \\
\hline Occipital lobe & $0.95(0.73-1.18)$ & $0.94(0.70-1.18)$ & $1.15(0.79-1.52)$ & $-0.20(-0.63$ to 0.23$), 0.73$ & $-0.21(-0.66$ to 0.24$), 0.71$ \\
\hline Caudate nucleus & $0.47(0.27-0.66)$ & $0.42(0.14-0.70)$ & $0.61(0.38-0.84)$ & $-0.14(-0.50$ to 0.22$), 0.98$ & $-0.19(-0.57$ to 0.19$), 0.61$ \\
\hline Nucleus accumbens & $1.39(0.96-1.81)$ & $1.23(0.87-1.58)$ & $1.53(1.19-1.88)$ & $-0.15(-0.76$ to 0.46$), 1.00$ & $-0.31(-0.95$ to 0.34$), 0.69$ \\
\hline Lentiform nucleus & $1.17(0.84-1.50)$ & $1.09(0.77-1.40)$ & $1.44(1.04-1.83)$ & $-0.26(-0.80$ to 0.27$), 0.64$ & $-0.35(-0.91$ to 0.22$), 0.38$ \\
\hline Thalamus & $1.43(1.01-1.84)$ & $1.31(1.02-1.61)$ & $1.63(1.24-2.02)$ & $-0.20(-0.80$ to 0.39$), 1.00$ & $-0.32(-0.94$ to 0.31$), 0.61$ \\
\hline Cerebellum & $1.08(0.78-1.38)$ & $0.98(0.68-1.28)$ & $1.26(0.92-1.59)$ & $-0.18(-0.66$ to 0.31$), 1.00$ & $-0.28(-0.79$ to 0.23$), 0.52$ \\
\hline Midbrain & $1.45(1.03-1.86)$ & $1.38(1.02-1.73)$ & $1.78(1.37-2.18)$ & $-0.33(-0.95$ to 0.29$), 0.54$ & $-0.40(-1.06$ to 0.25$), 0.38$ \\
\hline Pons & $1.58(1.04-2.11)$ & $1.44(1.05-1.83)$ & $1.88(1.41-2.34)$ & $-0.30(-1.05$ to 0.45$), 0.95$ & $-0.44(-1.23$ to 0.36$), 0.51$ \\
\hline
\end{tabular}

Abbreviations: $\mathrm{BP}_{\mathrm{ND}}=$ nondisplaceable binding potential; $\mathrm{CFS}=$ chronic fatigue syndrome; $\mathrm{HS}=$ healthy subject; $\mathrm{QFS}=\mathrm{Q}$ fever fatigue syndrome. Data are depicted as mean (difference) with $95 \%$ CI. A 1-way ANOVA with post hoc Bonferroni ( ${ }^{a}$ ) was used for comparing QFS and CFS with HS.

Whether binding of the $\left[{ }^{11} \mathrm{C}\right]$-PK11195 ligand is considered enhanced, normal, or even lowered may be explained by this difference in methodology.

Regarding the effect of disease duration, Hornig et al. previously reported that the inflammatory response, determined by cytokine measurements, is lower in patients with CFS with a long duration, that is, $>39$ months, of illness than in those with a short duration, that is, $<39$ months, of illness. ${ }^{34}$ In a previous study, however, we were unable to confirm these findings. ${ }^{13}$ We found that patients with CFS, who had fatigue for a median of 240 months, show less signs of neuroinflammation than patients with QFS, who were fatigued for a median of 84 months. Given previous findings by Hornig et al. and our observation that HSs generally showed a stronger signal of TSPO binding than patients, one could speculate that neuroinflammation wanes off over time and is followed by a refractory period with decreased expression of TSPO. Furthermore, studies on peripheral inflammatory cell metabolism in patients with CFS and QFS have repeatedly shown that mitochondria of these cells are likely to be affected. ${ }^{35-37}$ As TSPO is expressed in the outer mitochondrial membrane, it could be conceived that its expression is similarly affected in chronically fatigued patients. In liue of further speculation, we implore a large longitudinal investigation of TSPO expression in the mitochondrial membrane of chronically fatigued patients and relate findings to symptom severity scores. 
Figure 2 Correlation Between BPND of [ $\left.{ }^{11} \mathrm{C}\right]-\mathrm{PK} 11195$ in Various Brain Regions With CIS Questionnaire, Subscale on Fatigue Severity, Scores in Patients With QFS, Patients With CFS, and HSS

A

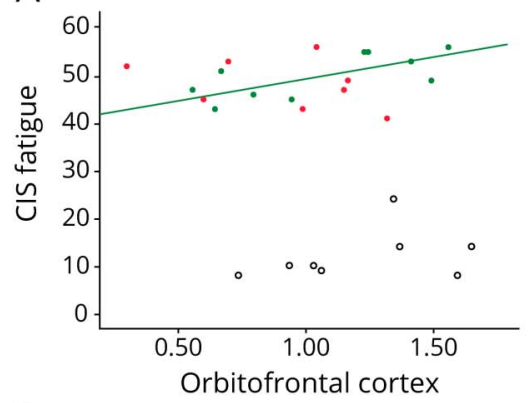

D

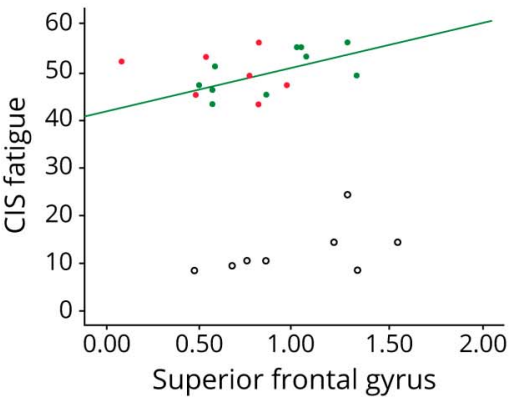

G

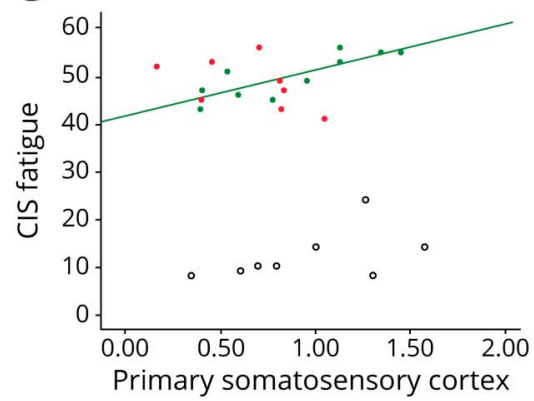

B

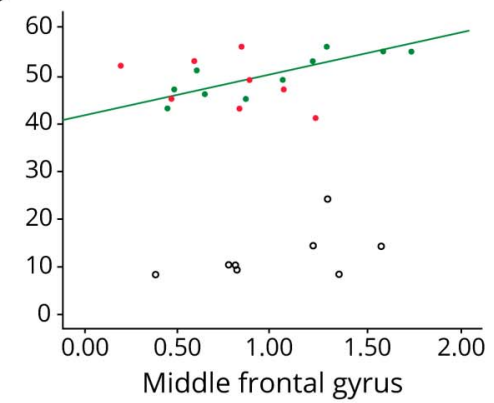

$\mathrm{E}$

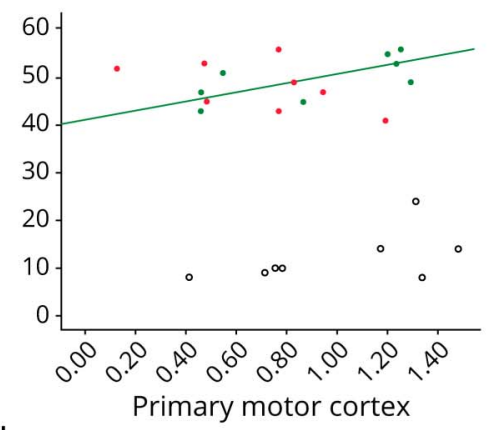

$\mathrm{H}$

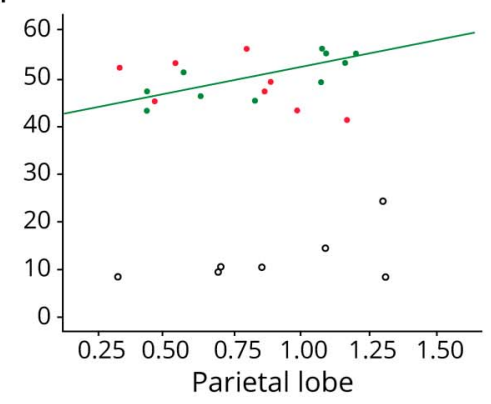

C

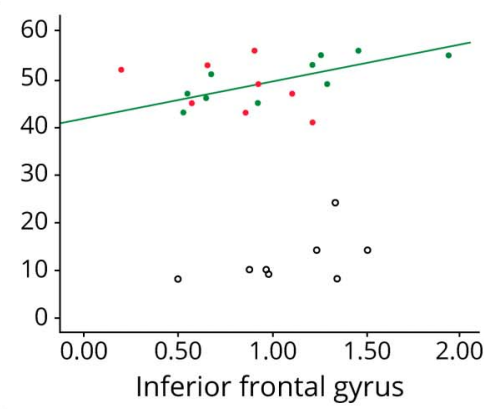

$\mathrm{F}$

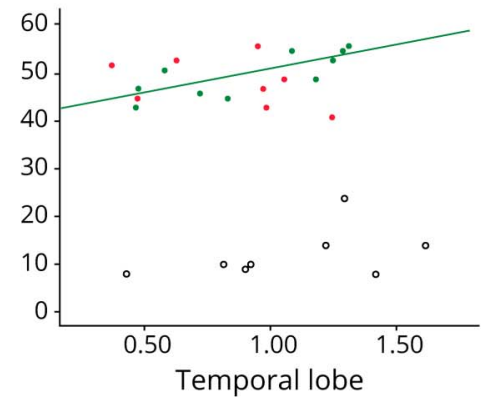

I

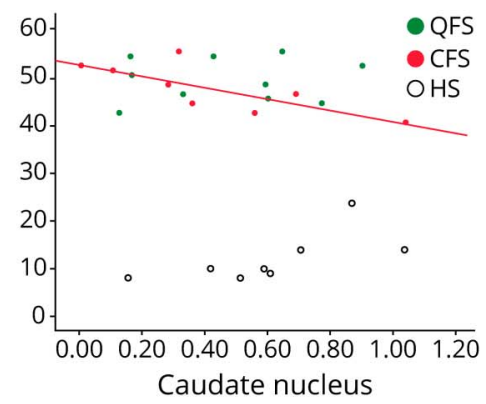

Scatter plots showing significant correlations between $\mathrm{BP}_{\mathrm{ND}}$ of $\left[{ }^{11} \mathrm{C}\right]-\mathrm{PK} 11195$ and fatigue severity, measured by the CIS questionnaire, subscale on fatigue severity, for patients with QFS; in the orbitofrontal cortex $\left(A, R=0.70^{*}\right)$, middle frontal gyrus $\left(B, R=0.83^{* *}\right)$, inferior frontal gyrus $\left(C, R=0.78^{* *}\right)$, superior frontal gyrus $\left(D, R=0.64^{*}\right)$, primary motor cortex $\left(E, R=0.74^{*}\right)$, temporal lobe $\left(F, R=0.78^{\star *}\right)$, primary somatosensory cortex $\left(G, R=0.83^{\star *}\right)$, and parietal lobe $\left(\mathrm{H}, \mathrm{R}=0.77^{* *}\right)$, and patients with $\mathrm{CFS}$; in the caudate nucleus $\left(\mathrm{I}, \mathrm{R}=-0.78^{\star}\right)$. $\mathrm{BP}_{\mathrm{ND}}=$ nondisplaceable binding potential; $\mathrm{CFS}=$ chronic fatigue syndrome; $\mathrm{HS}=$ healthy subject; QFS = Q fever fatigue syndrome. Statistical significance was attained if $p<0.05$.

An inherent problem in CFS research is the presumed heterogeneity of the disorder. We addressed this problem in several ways. As mentioned above, we only enrolled adult women. Second, we used a validated test panel of instruments to assess fatigue and disability. Third, we included a group of patients with postinfectious fatigue related to antecedent $Q$ fever (QFS). As in the latter group, an infectious, and therefore inflammatory, etiology was the precipitating factor, we would have expected this group in particular to exhibit signs of neuroinflammation. However, although $\mathrm{BP}_{\mathrm{ND}}$ of $\left[{ }^{11} \mathrm{C}\right]-\mathrm{PK} 11195$ was generally higher than in patients with CFS, even in this well-defined group, we could not detect neuroinflammation. For future perspective, we should avoid previous mistakes in CFS research and continue investigating neuroinflammation in chronic fatigue by using strict and uniform in- and exclusion criteria, together with well-defined control groups. ${ }^{4,38}$
Our study has some limitations. For reasons of homogeneity, we chose to use the $\left[{ }^{11} \mathrm{C}\right]$-PK11195 ligand as this was the ligand used by the only neuroinflammation PET imaging study in CFS by Nakatomi et al. ${ }^{5}$ Nowadays, a new generation of more sensitive ligands such as $\left[{ }^{11} \mathrm{C}\right]$-PBR28 and $\left[{ }^{18} \mathrm{~F}\right]$-DPA-714 are available, and perhaps even preferable, when taking allelic dependence of affinity into account. ${ }^{16}$ Using $\left[{ }^{11} \mathrm{C}\right]-\mathrm{PBR} 28$ for example, signs of neuroinflammation have been found in functional somatic syndromes such as fibromyalgia and GulfWar Illness. ${ }^{27,39}$ The former study included mostly women, whereas the latter included mostly men, but with complaints for up to 30 years. Another limitation is the large amount of correlations that were conducted, which increases the risk of a type 1 error (whereas post hoc analyses increase the risk of a type 2 error). A final limitation is the small number of subjects included in both our study and the study by Nakatomi et al. One could argue that a more sensitive new 
Figure 3 Correlation Between BPND of $\left[{ }^{11} \mathrm{C}\right]-\mathrm{PK} 11195$ in Various Brain Regions With CDC Questionnaire, Subscale on Complaints, Scores in Patients With QFS, Patients With CFS, and HSS
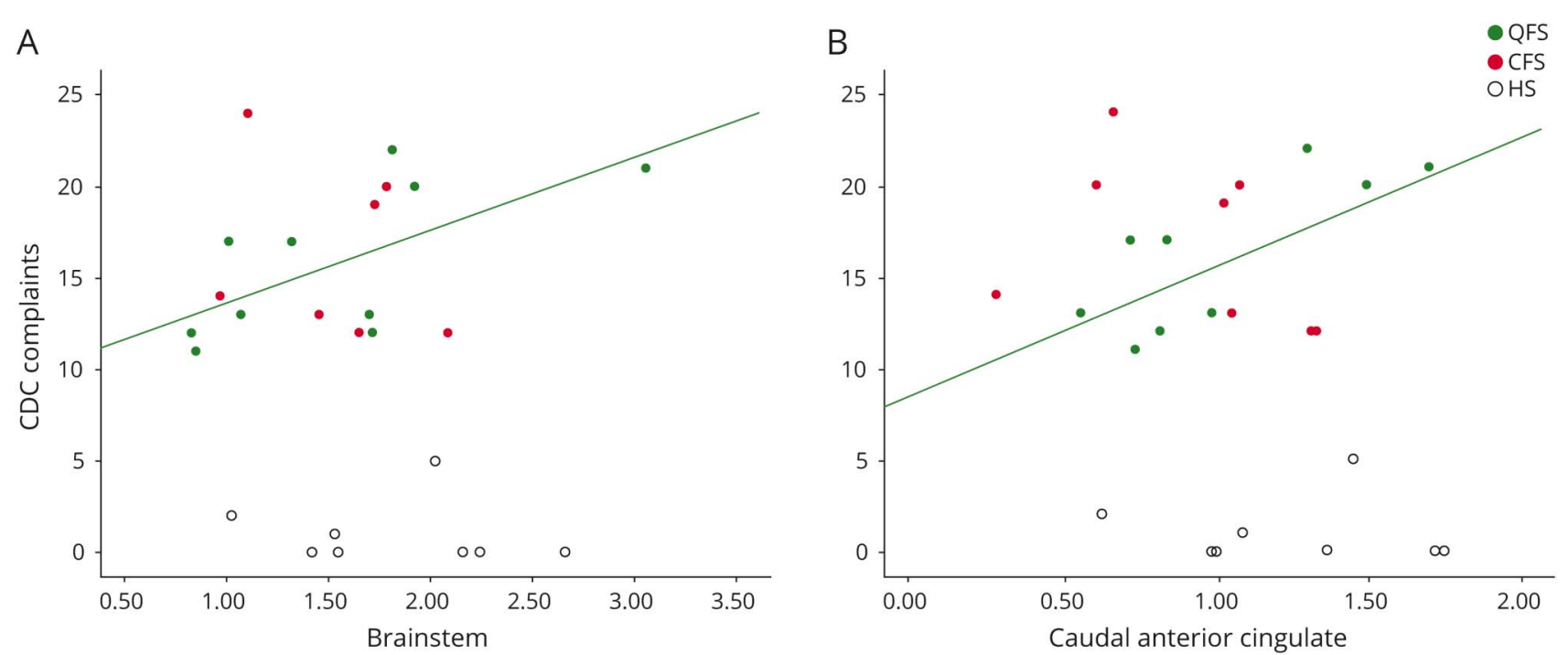

C
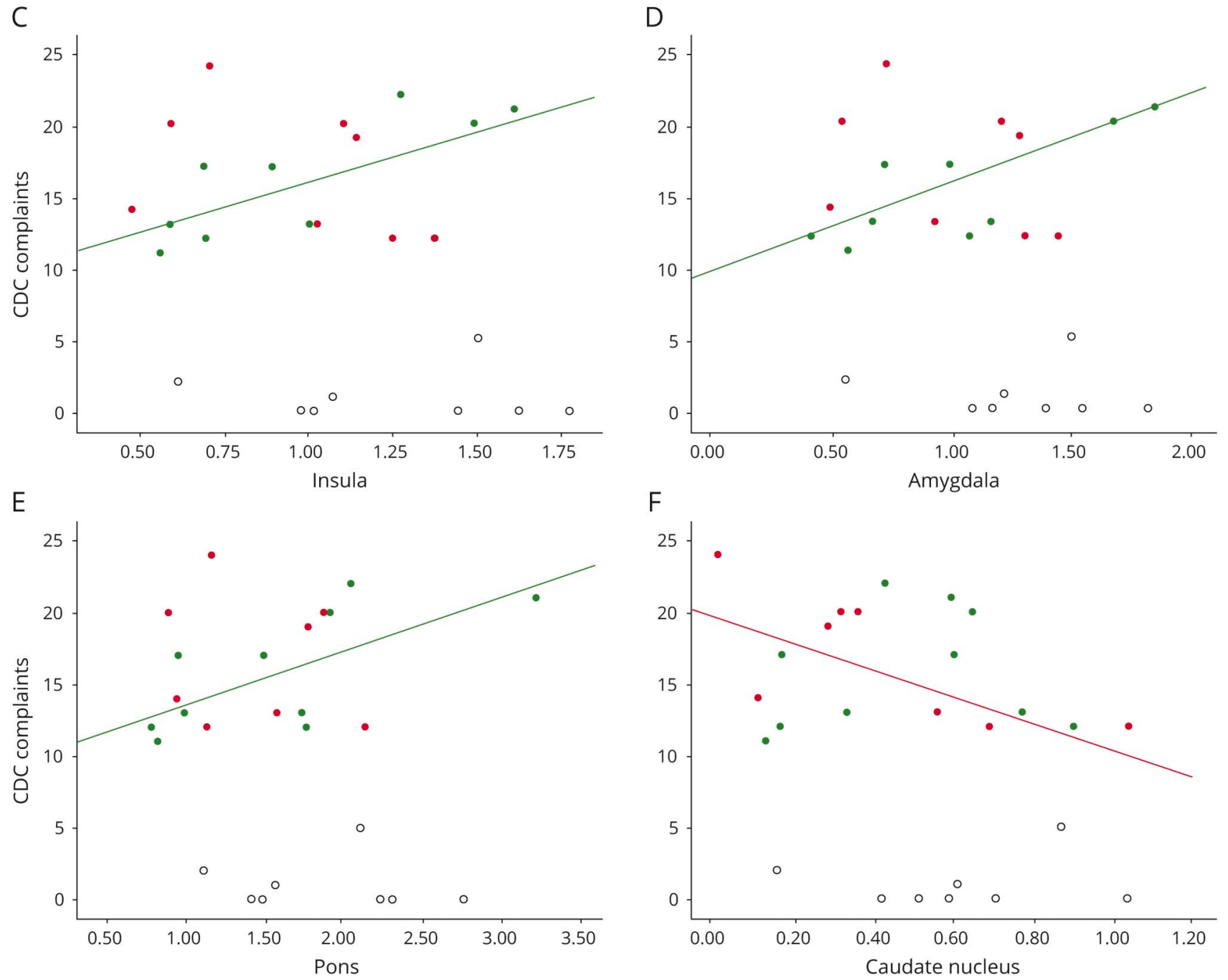

Scatter plots showing significant correlations between $\mathrm{BP}_{\mathrm{ND}}$ of $\left[{ }^{11} \mathrm{C}\right]-\mathrm{PK} 11195$ and fatigue severity, measured by the CDC questionnaire, subscale on complaints, for patients with QFS; the brainstem $\left(A, R=0.66^{*}\right)$, caudal anterior cingulate $\left(B, R=0.64^{*}\right)$, insula $\left(C, R=0.65^{*}\right)$, amygdala $\left(D, R=0.71^{*}\right)$, and pons $(E$, $\left.\mathrm{R}=0.69^{*}\right)$, and patients with CFS; in the caudate nucleus $\left(F, R=-0.73^{*}\right)$. BP $P_{N D}=$ nondisplaceable binding potential; $C D C=C$ enters for Disease Control; $C F S=$ chronic fatigue syndrome; HS = healthy subject; QFS = Q fever fatigue syndrome. Statistical significance was attained if $p<0.05$. 
generation ligand would be better suited when using such small numbers. ${ }^{40}$ Other than imploring a larger study or using more sensitive TSPO ligands, we should keep an eye on current investigations on other targets than TSPO for PET neuroimaging. ${ }^{41}$

In contrast to what was previously reported, our wellcontrolled study shows no significant difference in $\mathrm{BP}_{\mathrm{ND}}$ of $\left[{ }^{11} \mathrm{C}\right]$-PK11195 when comparing both patients with CFS and QFS with HSs. A larger and preferably longitudinal study, including both men and women together with well-matched controls, is needed to confirm whether chronically fatigued patients exhibit neuroinflammation. For this study, we propose using a new generation ligand with kinetic modeling via an arterial input function.

\section{Acknowledgment}

The authors thank Professor I.E.C. Sommer for her contributions to the inclusion of subjects in our study.

\section{Study Funding}

This study was funded by the Q-support Foundation (UMCN-140928-00). The was no role for the funding body in the design of the study, collection of data, analysis, interpretation of data, or writing of the manuscript.

\section{Disclosure}

The authors declare that they have no competing interests or financial relationships relevant to the manuscript. Go to Neurology.org/NN for full disclosures.

\section{Publication History}

Received by Neurology: Neuroimmunology \& Neuroinflammation May 20, 2021. Accepted in final form September 15, 2021.

Appendix Authors

\begin{tabular}{|c|c|c|}
\hline Name & Location & Contribution \\
\hline $\begin{array}{l}\text { Ruud } \\
\text { Raijmakers, } \\
\text { MSc }\end{array}$ & $\begin{array}{l}\text { Radboud Expertise Center } \\
\text { for Q fever, Department of } \\
\text { Internal Medicine and } \\
\text { Radboud Center for } \\
\text { Infectious Diseases, } \\
\text { Radboud University } \\
\text { Medical Center; Department } \\
\text { of Internal Medicine, } \\
\text { Radboud University Medical } \\
\text { Center, Nijmegen, the } \\
\text { Netherlands }\end{array}$ & $\begin{array}{l}\text { Drafting/revision of the } \\
\text { manuscript for content, } \\
\text { including medical writing } \\
\text { for content, major role in } \\
\text { the acquisition of data, } \\
\text { study concept or design, } \\
\text { and analysis or } \\
\text { interpretation of data }\end{array}$ \\
\hline $\begin{array}{l}\text { Megan } \\
\text { Roerink, MD }\end{array}$ & $\begin{array}{l}\text { Department of Internal } \\
\text { Medicine, Radboud University } \\
\text { Medical Center, Nijmegen, the } \\
\text { Netherlands }\end{array}$ & $\begin{array}{l}\text { Major role in the } \\
\text { acquisition of data and } \\
\text { analysis or interpretation } \\
\text { of data }\end{array}$ \\
\hline $\begin{array}{l}\text { Stephan } \\
\text { Keijmel, MD }\end{array}$ & $\begin{array}{l}\text { Radboud Expertise Center for } \\
\text { Q fever, Department of } \\
\text { Internal Medicine and } \\
\text { Radboud Center for } \\
\text { Infectious Diseases, Radboud } \\
\text { University Medical Center; } \\
\text { Department of Internal } \\
\text { Medicine, Radboud University } \\
\text { Medical Center, Nijmegen, } \\
\text { the Netherlands }\end{array}$ & $\begin{array}{l}\text { Major role in the } \\
\text { acquisition of data and } \\
\text { analysis or interpretation } \\
\text { of data }\end{array}$ \\
\hline
\end{tabular}

Appendix (continued)

\begin{tabular}{lll}
\hline Name & Location & Contribution \\
\hline Leo Joosten, & Radboud Expertise Center for & Drafting/revision of the \\
PhD, MD & Q fever, Department of & manuscript for content, \\
& Internal Medicine and & including medical writing \\
& Radboud Center for Infectious & for content \\
& Diseases, Radboud University & \\
& Medical Center; Department of & \\
& Internal Medicine, Radboud & \\
& University Medical Center, & \\
& Nijmegen, the Netherlands & \\
\end{tabular}

Mihai Netea, Radboud Expertise Center for

PhD, MD Q fever, Department of Internal Medicine and Drafting/revision of the manuscript for content, Radboud Center for Infectious for content Diseases, Radboud University Medical Center; Department of Internal Medicine, Radboud University Medical Center, Nijmegen, the Netherlands

\begin{tabular}{lll}
\hline Jos van der & Radboud Expertise Center for & Drafting/revision of the \\
Meer, PhD, & Q fever, Department of & manuscript for content, \\
MD & Internal Medicine and & including medical writing \\
& Radboud Center for & for content; Major role in \\
Infectious Diseases, Radboud & the acquisition of data; \\
& $\begin{array}{l}\text { University Medical Center; } \\
\text { Department of Internal }\end{array}$ & Study concept or design; \\
& Medicine, Radboud & Analysis or interpretation \\
& Oniversity Medical & \\
& Center, Nijmegen, the & \\
& Netherlands & \\
\end{tabular}

Hans Knoop, Department of Medical PhD, MD Psychology, Amsterdam University Medical Centers, Amsterdam Public Health Research Institute, University of Amsterdam, the Netherlands

\begin{tabular}{|c|c|c|}
\hline $\begin{array}{l}\text { Hans Klein, } \\
\text { MD }\end{array}$ & $\begin{array}{l}\text { Department of Psychiatry, } \\
\text { University of Groningen, } \\
\text { University Medical Center } \\
\text { Groningen, the Netherlands }\end{array}$ & Study concept or design \\
\hline $\begin{array}{l}\text { Chantal } \\
\text { Bleeker- } \\
\text { Rovers, PhD, } \\
\text { MD }\end{array}$ & $\begin{array}{l}\text { Radboud Expertise Center for } \\
\text { Q fever, Department of } \\
\text { Internal Medicine and } \\
\text { Radboud Center for Infectious } \\
\text { Diseases, Radboud University } \\
\text { Medical Center; } \\
\text { Department of Internal } \\
\text { Medicine, Radboud } \\
\text { University Medical } \\
\text { Center, Nijmegen, the } \\
\text { Netherlands }\end{array}$ & $\begin{array}{l}\text { Drafting/revision of the } \\
\text { manuscript for content, } \\
\text { including medical writing } \\
\text { for content; Major role in } \\
\text { the acquisition of data; } \\
\text { Study concept or design; } \\
\text { Analysis or interpretation } \\
\text { of data }\end{array}$ \\
\hline $\begin{array}{l}\text { Janine } \\
\text { Doorduin, } \\
\text { MD }\end{array}$ & $\begin{array}{l}\text { Department of Nuclear } \\
\text { Medicine and Molecular } \\
\text { Imaging, University of } \\
\text { Groningen, University Medical } \\
\text { Center Groningen, the } \\
\text { Netherlands }\end{array}$ & $\begin{array}{l}\text { Drafting/revision of the } \\
\text { manuscript for content, } \\
\text { including medical writing } \\
\text { for content; Major role in } \\
\text { the acquisition of data; } \\
\text { Study concept or design; } \\
\text { Analysis or interpretation } \\
\text { of data }\end{array}$ \\
\hline
\end{tabular}

\section{References}

1. Fukuda K, Straus SE, Hickie I, Sharpe MC, Dobbins JG, Komaroff A. The chronic fatigue syndrome: a comprehensive approach to its definition and study. International Chronic Fatigue Syndrome Study Group. Ann Intern Med. 1994; 121(12):953-959.

2. Naviaux RK, Naviaux JC, Li K, et al. Metabolic features of chronic fatigue syndrome. Proc Natl Acad Sci U S A. 2016;113(37):E5472-E5480.

3. Roerink ME, Roerink S, Skoluda N, et al. Hair and salivary cortisol in a cohort of women with chronic fatigue syndrome. Horm Behav. 2018;103:1-6. 
4. Blundell S, Ray KK, Buckland M, White PD. Chronic fatigue syndrome and circulating cytokines: a systematic review. Brain Behav Immun. 2015;50:186-195.

5. Nakatomi Y, Mizuno K, Ishii A, et al. Neuroinflammation in patients with chronic fatigue syndrome/myalgic encephalomyelitis: an (1)(1)C-(R)-PK11195 PET study. J Nucl Med. 2014;55(6):945-950.

6. Janse A, Nikolaus S, Wiborg JF, et al. Long-term follow-up after cognitive behaviour therapy for chronic fatigue syndrome. J Psychosom Res. 2017;97:45-51.

7. Galbraith S, Cameron B, Li H, Lau D, Vollmer-Conna U, Lloyd AR. Peripheral blood gene expression in postinfective fatigue syndrome following from three different triggering infections. J Infect Dis 2011;204(10):1632-1640.

8. Cameron B, Hirschberg DL, Rosenberg-Hassan Y, Ablashi D, Lloyd AR. Serum cytokine levels in postinfective fatigue syndrome. Clin Infect Dis 2010;50(2):278-279.

9. Morroy G, Keijmel SP, Delsing CE, et al. Fatigue following acute Q-fever: a systematic literature review. PLoS One. 2016;11(5):e0155884.

10. Shannon M. The Post Q Fever Debility \& Fatigue Syndrome: An Epidemiological Study. University of Adelaide; 1993

11. Keijmel SP, Saxe J, van der Meer JW, et al. A comparison of patients with Q fever fatigue syndrome and patients with chronic fatigue syndrome with a focus on inflammatory markers and possible fatigue perpetuating cognitions and behaviour. J Psychosom Res. 2015;79(4):295-302.

12. Raijmakers RPH, Koeken V, Jansen AFM, et al. Cytokine profiles in patients with $Q$ fever fatigue syndrome. J Infect. 2019;78(5):349-357.

13. Roerink ME, Knoop H, Bronkhorst EM, et al. Cytokine signatures in chronic fatigue syndrome patients: a case control study and the effect of anakinra treatment. J Transl Med. 2017;15(1):267.

14. Prinz M, Priller J. Microglia and brain macrophages in the molecular age: from origin to neuropsychiatric disease. Nat Rev Neurosci. 2014;15(5):300-312.

15. Haley MJ, Brough D, Quintin J, Allan SM. Microglial priming as trained immunity in the brain. Neuroscience. 2019;405:47-54.

16. VanElzakker MB, Brumfield SA, Lara Mejia PS. Neuroinflammation and cytokines in myalgic encephalomyelitis/chronic fatigue syndrome (ME/CFS): a critical review of research methods. Front Neurol. 2018;9:1033.

17. Hornig M, Gottschalk CG, Eddy ML, et al. Immune network analysis of cerebrospinal fluid in myalgic encephalomyelitis/chronic fatigue syndrome with atypical and classical presentations. Transl Psychiatry. 2017;7(4):e1080.

18. Mueller C, Lin JC, Sheriff S, Maudsley AA, Younger JW. Evidence of widespread metabolite abnormalities in Myalgic encephalomyelitis/chronic fatigue syndrome: assessment with whole-brain magnetic resonance spectroscopy. Brain Imaging Behav. 2020;14(2):562-572.

19. Natelson BH, Weaver SA, Tseng CL, Ottenweller JE. Spinal fluid abnormalities in patients with chronic fatigue syndrome. Clin Diagn Lab Immunol. 2005;12(1):52-55.

20. Natelson BH, Vu D, Coplan JD, et al. Elevations of ventricular lactate levels occur in both chronic fatigue syndrome and fibromyalgia. Fatigue. 2017;5(1):15-20.

21. Shungu DC, Weiduschat N, Murrough JW, et al. Increased ventricular lactate in chronic fatigue syndrome. III. Relationships to cortical glutathione and clinical symptoms implicate oxidative stress in disorder pathophysiology. NMR Biomed. 2012;25(9):1073-1087.

22. Reeves WC, Lloyd A, Vernon SD, et al. Identification of ambiguities in the 1994 chronic fatigue syndrome research case definition and recommendations for resolution. BMC Health Serv Res. 2003;3(1):25.
23. Vercoulen JH, Swanink CM, Fennis JF, Galama JM, van der Meer JW, Bleijenberg G Dimensional assessment of chronic fatigue syndrome. J Psychosom Res. 1994;38(5): 383-392.

24. Bergner M, Bobbitt RA, Carter WB, Gilson BS. The Sickness Impact Profile: development and final revision of a health status measure. Med Care. 1981;19(8):787-805.

25. Environment NIfPHat. Dutch Guideline Q Fever Fatigue Syndrome [in Dutch]; 2012. rivm.nl/dsresource?objectid=rivmp:118226\&type=org\&disposition=inline $($ accessed on 02-01-2021).

26. Doorduin J, de Vries EF, Willemsen AT, de Groot JC, Dierckx RA, Klein HC. Neuroinflammation in schizophrenia-related psychosis: a PET study. J Nucl Med. 2009;50(11):1801-1807.

27. Albrecht DS, Forsberg A, Sandstrom A, et al. Brain glial activation in fibromyalgia - a multi-site positron emission tomography investigation. Brain Behav Immun. 2019;75: 72-83.

28. Beck AT, Ward CH, Mendelson M, Mock J, Erbaugh J. An inventory for measuring depression. Arch Gen Psychiatry. 1961;4:561-571.

29. Wagner D, Nisenbaum R, Heim C, Jones JF, Unger ER, Reeves WC. Psychometric properties of the CDC Symptom Inventory for assessment of chronic fatigue syndrome. Popul Health Metr. 2005;3:8.

30. Hammers A, Allom R, Koepp MJ, et al. Three-dimensional maximum probability atlas of the human brain, with particular reference to the temporal lobe. Hum Brain Mapp 2003;19(4):224-247.

31. Prins JB, van der Meer JW, Bleijenberg G. Chronic fatigue syndrome. Lancet. 2006; 367(9507):346-355.

32. Ter Horst R, Jaeger M, Smeekens SP, et al. Host and environmental factors influencing individual human cytokine responses. Cell. 2016;167(4):1111-1124 e13.

33. Villapol S, Loane DJ, Burns MP. Sexual dimorphism in the inflammatory response to traumatic brain injury. Glia. 2017;65(9):1423-1438.

34. Hornig M, Montoya JG, Klimas NG, et al. Distinct plasma immune signatures in ME/ CFS are present early in the course of illness. Sci Adv. 2015;1(1):e1400121.

35. Booth NE, Myhill S, McLaren-Howard J. Mitochondrial dysfunction and the pathophysiology of myalgic encephalomyelitis/chronic fatigue syndrome (ME/CFS). Int $J$ Clin Exp Med. 2012;5(3):208-220.

36. Tomas C, Brown A, Strassheim V, Elson JL, Newton J, Manning P. Cellular bioenergetics is impaired in patients with chronic fatigue syndrome. PLoS One. 2017; 12(10): 0186802.

37. Raijmakers RPH, Jansen AFM, Keijmel SP, et al. A possible role for mitochondrialderived peptides humanin and MOTS-c in patients with $Q$ fever fatigue syndrome and chronic fatigue syndrome. J Transl Med. 2019;17(1):157.

38. De Picker L, Morrens M. Perspective: solving the heterogeneity conundrum of TSPO PET imaging in psychosis. Front Psychiatry. 2020;11:362.

39. Alshelh Z, Albrecht DS, Bergan C, et al. In-vivo imaging of neuroinflammation in veterans with Gulf War illness. Brain Behav Immun. 2020;87:498-507.

40. Guo Q, Owen DR, Rabiner EA, Turkheimer FE, Gunn RN. Identifying improved TSPO PET imaging probes through biomathematics: the impact of multiple TSPO binding sites in vivo. Neuroimage. 2012;60(2):902-910.

41. Meyer JH, Cervenka S, Kim MJ, Kreisl WC, Henter ID, Innis RB. Neuroinflammation in psychiatric disorders: PET imaging and promising new targets. Lancet Psychiatry. 2020;7(12):1064-1074. 


\section{Neurology \\ Neuroimmunology \& Neuroinflammation}

\section{No Signs of Neuroinflammation in Women With Chronic Fatigue Syndrome or Q Fever Fatigue Syndrome Using the TSPO Ligand [ ${ }^{11}$ C]-PK11195 \\ Ruud Raijmakers, Megan Roerink, Stephan Keijmel, et al. \\ Neurol Neuroimmunol Neuroinflamm 2022;9; \\ DOI 10.1212/NXI.0000000000001113}

This information is current as of November 23, 2021

Updated Information \&

Services

References

Permissions \& Licensing

Reprints including high resolution figures, can be found at:

http://nn.neurology.org/content/9/1/e1113.full.html

This article cites 39 articles, 4 of which you can access for free at: http://nn.neurology.org/content/9/1/e1113.full.html\#\#ref-list-1

Information about reproducing this article in parts (figures,tables) or in its entirety can be found online at:

http://nn.neurology.org/misc/about.xhtml\#permissions

Information about ordering reprints can be found online:

http://nn.neurology.org/misc/addir.xhtml\#reprintsus

Neurol Neuroimmunol Neuroinflamm is an official journal of the American Academy of Neurology.

Published since April 2014, it is an open-access, online-only, continuous publication journal. Copyright

Copyright $\odot 2021$ The Author(s). Published by Wolters Kluwer Health, Inc. on behalf of the American

Academy of Neurology.. All rights reserved. Online ISSN: 2332-7812.

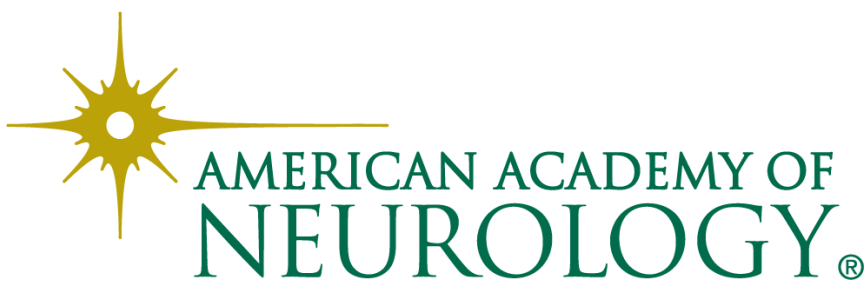

